\title{
Multi-Parametric Analysis of Aggressive Communication and Motivation Climate in Physical Education
}

\author{
Stergiani Deliligka, Alexandra Bekiari \\ Faculty of Physical Education and Sports Science, University of Thessaly, Trikala, Greece \\ Email: sandrab@pe.uth.gr
}

How to cite this paper: Deliligka, S., \& Bekiari, A. (2018). Multi-Parametric Analysis of Aggressive Communication and Motivation Climate in Physical Education. Psychology, 9, 179-203.

https://doi.org/10.4236/psych.2018.92012

Received: December 28, 2017

Accepted: February 9, 2018

Published: February 12, 2018

Copyright (C) 2018 by authors and Scientific Research Publishing Inc. This work is licensed under the Creative Commons Attribution International License (CC BY 4.0).

http://creativecommons.org/licenses/by/4.0/

\section{(c) (i) Open Access}

\begin{abstract}
The purpose of this study was to examine verbal aggressiveness, argumentativeness and motivation climate in a multi-parametric context. Nine hundred and three (903) students (448 males, 455 females), whose age varied from 10 to 17 years old $(M=13.8, S D=2.3)$, participated in this study. The findings revealed that instructors' verbal aggressiveness was positively related to performance climate and negatively to argumentativeness and mastery climate, while argumentativeness was positively related to mastery climate. Additionally, the multiple regression analysis presented that argumentativeness and the created motivational climate were negative predictors of verbal aggressiveness. High school students perceive their instructor more argumentative and reported the lower score on performance climate. Urban schools presented higher levels on verbal aggressiveness and performance climate. Students from $9^{\text {th }}$ grade proved to have higher score in verbal aggressiveness, $7^{\text {th }}$ grade in argumentativeness and mastery climate. Finally, students from $6^{\text {th }}$ grade perceived that their instructors created performance climate in higher levels. Furthermore, Mancova indicated that the covariates, mastery and performance climate explained a statistically significant proportion of variance of verbal aggressiveness and argumentativeness between classes. Moreover, instructors who use low level of verbal aggressiveness proved to have higher score in argumentativeness and mastery climate. Also, high level of verbal aggressiveness was presented in performance climate. Finally, Ancova reported that argumentativeness was a significant covariate of verbal aggressiveness on performance climate.
\end{abstract}

\section{Keywords}

Verbal Aggressiveness, Argumentativeness, Motivational Climate, Perceptions, PE Teachers, Students 


\section{Introduction}

\subsection{Aggressive Communication}

Aggressive communication composes a natural component of social behavior, aiming at satisfying the needs and goals (Hrázská, 2011). It violates social norms, reducing rights and people's integrity (Vagnerova, 2002). Aggressive communication is defined as an individual's effort to assail another person's self-esteem or positions on communicational matters (Infante, 1987). Aggressive behavioral attitudes predominate in human relations (Bekiari \& Hasanagas, 2015; 2016a; 2016b; 2016c). Verbal aggressiveness and argumentativeness are aggressive communicational variables and are related to people's predispositions (Infante, 1987). These traits affect individual's behavior concerning disagreements and controversies, or advocacies and refutations (Infante \& Rancer, 1993; Infante \& Rancer, 1996). Verbal aggressiveness is a destructive behavioral trait, whereas argumentativeness is a constructive one. A constructive behavior contributes to improving interpersonal communication and relationship, while the outcomes of a destructive one are damaging and hurtful among relationships and people's feelings (Avtgis, Rancer, Kanjeva, \& Chory, 2008; Infante, 1988; Infante \& Rancer, 1996; Rancer \& Avtgis, 2014). Argumentativeness predisposes an individual to adopt a firm position upon debatable subjects and contradict against the statements of arguers (Infante \& Rancer, 1982; 1996; Rancer \& Avtgis, 2014). It has been stated that it composes an important predictor of the actual dialectical behavior (Infante \& Rancer, 1996; Rancer \& Avtgis, 2006). On the other hand, a person's disposition to deprive of someone's dignity using inflictive expressions, leads to verbal aggressiveness (Infante \& Rancer, 1996; Infante \& Wigley, 1986). An individual's personality may reveal such element (Aloia \& Solomon, 2016; Goodboy \& Myers, 2012), although it is also resulted from the environmental conditions where the individual acts (Infante \& Rancer, 1996). Verbal aggressiveness imposes psychological pain and negative feelings on the receiver via attacks on the character, the ability, in appearance and in the background, contempt, ridicule, threats, profanity, curses, loud voices, teasing gestures (Avtgis \& Rancer, 2010; Coyne \& Archer, 2004; Infante 1987; Infante, Sabourin, Rudd, \& Shannon, 1990; Infante, Riddle, Horvath, \& Tumlin, 1992; Infante \& Wigley, 1986; Neuman \& Baron, 1997; Rancer \& Avtig, 2006) and additionally through work ethic attacks and nonverbal behaviors (Myers, Brann, \& Martin, 2013). Verbal aggressiveness negative consequences persevere apart from the form of interlocutors' relationship (Aloia \& Solomon, 2016; Bekiari, 2012; Edwards \& Myers, 2007; Hasanagas \& Bekiari, 2017a, 2017b; Hasanagas, Bekiari, \& Vasilos, 2017; Infante \& Rancer, 1996; Martin, Anderson, \& Horvath, 1996; Myers \& Buerkel, 1994; Theoharis \& Bekiari, 2017; 2018; Theoharis, Bekiari, \& Koustelios, 2017). Teachers who engage in aggressive behaviors may lack argumentative skills because they are not capable of approaching arguments (Bekiari, 2016; Deliligka, Bekiari, \& Syrmpas, 2017; Infante \& Rancer, 1996; Syrmpas \& Bekiari, 2015). These individuals defend themselves by aggressive attacks against the other (Infante, 1995). 
Aggressive communication in a classroom, derived from teachers, can affect incomparably the teaching and learning environment, as well as the students' commitment and absorption (Bekiari, 2012; Bekiari, Kokaridas, \& Sakellariou, 2006; Rancer \& Avtgis, 2006; Myers \& Rocca, 2001; Rocca, 2004; Myers, Edwards, Wahl, \& Martin, 2007). Verbal aggressiveness has widespread considerably in educational context (Bekiari, Koustelios, \& Sakellariou, 2000). In such conditions students become less motivated, less satisfied, less interested and concentrated (Bekiari, 2014; 2016; Bekiari, Deliligka, \& Hasanagas, 2017; Bekiari, Kokaridas, \& Sakellariou, 2005; 2006; Bekiari \& Tsiana, 2016; Manoli \& Bekiari, 2015; Mazer \& Stowe, 2016; Myers, 2002; Snyder, Forbus, \& Cistulli, 2012; Weiss \& Houser, 2007), more Machiavellian, having more anxiety and using bullying (Bekiari \& Pachi, 2017; Bekiari, Pachi, \& Hasanagas, 2017; Bekiari, et al, 2006; Bekiari \& Spanou, 2018). Teachers' verbal aggressiveness towards their students is negatively related to affective learning (Bekiari, 2012; Bekiari \& Tsaggopoulou, 2016), interpersonal attraction and sympathy (Bekiari \& Petanidis, 2016; Bekiari \& Spyropoulou, 2016; Bekiari \& Sakellariou, 2003; Syrmpas \& Bekiari, 2015). The most common aggressive messages that are used by verbally aggressive teachers are attacks on students' character, competence attacks, irony, cursing, swearing, threats, ridicule, teasing and nonverbal emblems (Bekiari, Kokaridas, \& Sakellariou, 2005; Deliligka, Bekiari, \& Syrmpas, 2017; Infante et al., 1992; Infante et al., 1990; Infante \& Rancer, 1993). Argumentativeness is considered a beneficial and effective social practice, comparing to verbal aggressiveness, in order to negotiate differences (Bekiari, Deliligka, \& Koustelios, 2016; Bekiari \& Ntakou, 2018; Johnson, Becker, Wigley, Haigh, \& Craig, 2007). Argumentative teachers promote unity between students, motivation, cognitive learning, satisfaction and excitement during the learning process (Bekiari \& Balla, 2017; Bekiari, Nikolaidou, \& Hasanagas, 2017; Bekiari \& Pylarinou, 2017; Hamilton \& Hample, 2011). Assertiveness, intimacy, competence (Myers, 1998), efficiency concerning the teaching process, amiability (Syrmpas \& Bekiari, 2015) and reliability (Schrodt, 2003) form characteristics of argumentative teachers as they are perceived by their students. Argumentativeness is positively correlated with social, physical and learning attractiveness (Syrmpas \& Bekiari, 2015), intrinsic reasons for discipline (Bekiari \& Pylarinou, 2017) and affective learning (Bekiari \& Manoli, 2016). Practicing in argumentativeness based on the theory of argumentative skill deficiency model (Infante, Chandler, \& Rudd, 1989), encourages young people to use it in conversations, as a result to promote argumentativeness and avoid verbal aggressiveness, reducing thereby the prevalence of physical aggression in society (Infante, 1987; Infante et al., 1992; Infante, Trebing, Shepherd, \& Seeds, 1984; Rancer, Avtgis, Kosberg, \& Whitecap, 2000).

\subsection{Motivational Climate}

Motivational climate can be defined as a communicative environment which addresses the targets of a process in the direction of attainment situations and it 
is regulated by circumstantial effects (Ames, 1992a), such as "significant others" (e.g. teachers, parents, peers) (Duda \& Ntoumanis, 2005; Roberts \& Treasure, 1992). The concept of motivational climate has derived from the Achievement Goal Theory and its distinction is twofold, that is mastery or task-involving climate and performance or ego-involving climate (AGT; Ames, 1992b; Ames \& Archer, 1988; Maehr \& Nicholls, 1980, Nicholls, 1984, 1989; Roberts, Treasure, \& Conroy, 2007). Teachers' impact is significant and involves many sides because they can inspire and reassure the students' effective engagement both during the learning process and furthermore (Granero-Gallegos, Baena-Extremera, Gómez-López, \& Abraldes, 2014). Studies have reported that attitudes and intercommunications are elements which are engaging in motivational climate, for instance interactive motivation between peers, based on the intention to foster competition, encouragement, collaboration and endearment (Beltman \& Volet, 2007; Bengoechea \& Strean, 2007; Keegan, Harwood, Spray, \& Lavallee, 2009; Keegan et al., 2010; Vazou, Ntoumanis, \& Duda, 2005; Weiss, Amorose, \& Wilko, 2009). The positive outcomes of mastery climate are numerous, because its main emphasis is given to learning and cooperation (Bortoli, Bertollo, Vitali, Filho, \& Robazza, 2015). The students are emboldened with advanced abilities, cooperative learning, personal enrichment and commending for each endeavor (Ames, 1992a; Roberts et al., 2007). Furthermore through mastery climate, intrinsic motivation (Bryan \& Solmon, 2012; Ommundsen \& KvalØ, 2007; Papaioannou, 1995; Spittle \& Byrne, 2009; Standage \& Gillison, 2007), self-assessment and contentment are stimulated (Atkins, Johnson, Force, \& Petrie, 2015; Kavussanu \& Harnisch, 2000; Le Bars, Gernigon, \& Ninot, 2009). Moreover, expanded research has indicated mastery's climate positive relation with accomplishments, satisfaction, importunity in every attempt, flexibility (Ntoumanis \& Biddle, 1999; Roberts, 2012; Van De Pol, Kavussanu, \& Ring, 2012), as well as decreased anxiety, commitment, engagement, enthusiasm, assurance, integrity (Atkins et al., 2015; Braithwaite, Spray, \& Warburton, 2011; Cunningham \& Xiang, 2008; Kavussanu \& Roberts, 1998; Mouratidis, Vansteenkiste, Lens, \& Vanden Auweele, 2009; Smith, Smoll, \& Cumming, 2007). Performance motivational climate is based essentially on social comparison and competition, arousing negative emotions on students such as nervousness and distraction (Bortoli et al., 2015; Liukkonen, Barkoukis, Watt, \& Jaakkola, 2010). Throughout the course that focuses on performance motivational climate, teachers emphasize on regulative assessment, display of students' abilities and praising their best efficiency (Ames, 1992b; Ames \& Archer, 1988; Keegan et al., 2010; Murcia, Camacho, \& Rodríguez, 2008). Therefore, performance motivational climate cultivates students' dissatisfaction, lack of interest and endeavor, commitment incongruity, as well as disengage as results of amotivation (Braithwaite et al., 2011; Cumming, Smoll, Smith, \& Grossbard, 2007; Granero-Gallegos et al., 2014; Liukkonen et al., 2010; Nerstad, Roberts, \& Richardsen, 2013; Ntoumanis \& Biddle, 1999; Ommundsen \& KvalØ, 2007; Van De Pol et al., 2012). 


\subsection{Innovation and Questions of Study}

Allowing for the above literature review, the present study aimed at exploring relations among the perceived factors of instructors' aggressive communication (verbal aggressiveness, argumentativeness) and motivational climate during the physical education lessons in a multi-parametric approach. Thus, by examining these factors a more complete picture could be obtained concerning instructors' behavior and influential aspects, comprising an academic added value. The practical added value is expected to detect behaviors that restrain the effectiveness of the learning process and therefore to encounter such spreading educational parameters. In particular, this study intends to answer the following research questions:

- Is there a positive or negative relationship between perceived instructors' verbal aggressiveness, their argumentativeness and motivational climate in physical education classes?

- To what extend the perceived instructors' argumentativeness and motivational climate could be significant predictors of their use of verbal aggressiveness?

- Are there any differences noted between schools' region and students' school level, regarding verbal aggressiveness, argumentativeness and motivational climate?

- Are there any differences noted between gender and class, regarding verbal aggressiveness, argumentativeness and motivational climate?

- Are there any differences noted between gender and class, regarding verbal aggressiveness and argumentativeness, if only the motivational climate was perceived by the same?

- Are there any differences noted between low verbal aggressiveness, moderate and high verbal aggressiveness, regarding argumentativeness and motivational climate?

- Are there any differences noted between low verbal aggressiveness, moderate and high verbal aggressiveness, regarding performance climate, if only argumentativeness was perceived by the same way?

\section{Method}

\subsection{Participants and Procedure}

Nine hundred and three (903) students (448 males, 455 females) participated in this study. They were aged from 10 to 17 years old $(M=13.8, S D=2.3)$. Those participants studied in five primary schools at $5^{\text {th }}$ and $6^{\text {th }}$ grade, from $7^{\text {th }}$ to $9^{\text {th }}$ grade in five secondary schools and from $10^{\text {th }}$ to $12^{\text {th }}$ grade in five high schools. Their social and economic status varied. Those particular fifteen schools were randomly chosen from a wide range of schools listed in Central Greece. The location of schools belonged to urban, suburban and rural areas.

The completion of the questionnaires was referring to PE teachers' verbal aggressiveness, argumentativeness and motivational climate during the physical education lessons. The participants were informed thoroughly about the research. Their anonymous as well as voluntary engagement was also emphasized. 
Students' parents were asked to fill in a consent form. The researcher during the process was willing to assist and answer to any questions. Permission from the Greek Ministry of Education was obtained, prior to the research.

\subsection{Instruments}

The Greek version of the Verbal Aggressiveness questionnaire was applied (Bekiari \& Digelidis, 2015). It is based on the theoretical structure and Infante's and Wigley's (1986) Verbal Aggressiveness Questionnaire. Students' perceptions regarding physical education instructors' verbal aggressiveness, are determined through this instrument. There are eight items in the scale (e.g., "instructor derogates students", "instructor makes students feel bad"). Exploratory examination (Bekiari \& Digelidis, 2015) supported the psychometric properties of the instrument. Specifically, the fit indices were set in a satisfied level at the confirmatory factor analysis (CFI: 0.97, SRMR: 0.02), and there was also a high level of reliability $(\alpha=0.96)$. The responds were valued in a 5-point Likert-type scale ranging through 1: Strongly disagree to 5 : Strongly agree.

The Greek version of the Argumentativeness questionnaire was applied in this study (Syrmpas \& Bekiari, 2015), which relies on Myers and Rocca (2000) questionnaire. Instructors' argumentativeness is detected through students' perceptions. The scale consists of ten items (e.g., "my instructor is excited every time he/she tries to solve disagreements with the students", "my instructor enjoys defending his/her opinions on an issue"). Initial examination of the instrument confirmed the psychometric properties (Syrmpas \& Bekiari, 2015). Specifically, the fit indices were set in a satisfied level at the confirmatory factor analysis (CFI: 0.98, SRMR: 0.05), and there was also a high level of reliability ( $\alpha=0.87$ ). The responds were valued in a 5-point Likert-type scale ranging through 1: Strongly disagree to 5: Strongly agree.

The short version of the Learning and Performance Orientations in Physical Education Classes Questionnaire (LAPOPEQ) was used in order to value the Motivational climate (Papaioannou, 1994; 1998; Papaioannou, Marsh, \& Theodorakis, 2004). The questionnaire consists of two scales regarding students' perceptions about the motivational climate created by their instructors. The first-seven items are referring to mastery climate (e.g., "My instructor is mostly satisfied when every student learns something new") and the other six-items are referring to performance climate (e.g., "My instructor reinforces competition among his/her students"). It was found that through CFA (CFI = 0.98, RMSEA = 0.06) the motivational climate model adapted the data (Hu \& Bentler, 1999), and there was also a satisfied level of reliability ( $\alpha=$ between 0.74 and 0.87 ). The responds were rated in a 5-point Likert-type scale ranging through 1: Strongly disagree to 5: Strongly agree.

\subsection{Data Analysis}

The Statistical Package for Social Sciences (SPSS 21.0) was used for the data ana- 
lyses. The internal consistency of the factors was examined through Cronbach's a reliability analysis. The Pearson correlation coefficient was used to measure the correlation between the subscales of the questionnaires. A multiple hierarchical regression analysis was conducted in order to explore the extent to which the perceived instructors' argumentativeness and motivational climate could be significant predictors of their use of verbal aggressiveness. Argumentativeness which is considered as instructors' personality trait was used as the first predictor. Then mastery and performance motivational climate were included in the second stage of analysis aiming at predicting instructors' verbal aggressiveness. Through two-way MANOVAs analyses were examined differences in students' perceptions concerning their PE teachers' verbal aggressiveness, argumentativeness and motivational climate between schools' region and students' school level, as well as between students' gender and class. Moreover, differences in argumentativeness and motivational climate between the perceived level of verbal aggressiveness (low, moderate and high) were researched by performing one-way MANOVA analysis. Furthermore, after differences were indicated with prior findings, Univariate Analysis of Covarience (ANCOVA) was assessed having as covariate the argumentativeness and finally Multivariate Analysis of Covariance (MANCOVA) was performed using motivational climate as covariate. Due to the existing differences in MANOVAs, ANCOVA and MANCOVA were conducted to examine the differences with some variables being "partialled-out" of the procedure (Cohen \& Cohen, 1983) by taking the role of covariance, in order to assess the induction procedures. Statistical significance was set at 0.05 and Post hoc analyses were performed using Bonferroni test.

\section{Results}

Cronbach's a reliability analysis for the 8 -items verbal aggressiveness scale (Bekiari \& Digelidis, 2015) was 0.96, and for argumentativeness scales (Syrmpas \& Bekiari, 2015) was 0.89 . The factors of mastery climate $(\alpha=0.94)$ and performance climate $(\alpha=0.96)$ for the motivational climate scale (Papaioannou, 1994; 1998; Papaioannou, Marsh, \& Theodorakis, 2004) showed a high level of reliability as well. In addition, a correlation analysis was conducted, the results of which are presented in "Table 1". As it can be seen, there was a positive significant relationship between instructors' verbal aggressiveness and performance climate $(r=0.592)$, as well as between instructors' argumentativeness and mastery climate $(r=0.479)$. Moreover, instructors' verbal aggressiveness was negatively related to argumentativeness $(r=-0.766)$ and mastery climate $(r=-0.627)$. Also a negative significant relationship was showed between instructors' argumentativeness and performance climate $(r=-0.415)$, as well as mastery climate and performance climate $(r=-0.792)$. At the same time, "Table 1" presents the Cronbach's alpha, mean scores and standard deviations of the variables.

As "Table 2" indicates, a multiple hierarchical regression analysis was conducted to predict verbal aggressiveness from argumentativeness in the first step. 
Table 1. Reliabilities, Means, Standard Deviations and Pearson Correlations among variables.

\begin{tabular}{lccccccc}
\hline \multicolumn{1}{c}{ Factors } & $\alpha$ & $\mathrm{M}$ & $\mathrm{SD}$ & 1 & 2 & 3 & 4 \\
\hline 1) Verbal aggressiveness & 0.96 & 2.84 & 1.17 & - & & & \\
2) Argumentativeness & 0.89 & 2.74 & 0.42 & $-0.766^{* *}$ & - & & \\
3) Mastery climate & 0.94 & 3.46 & 0.97 & $-0.627^{* *}$ & $0.479^{* *}$ & - & \\
4) Performance climate & 0.96 & 2.77 & 1.13 & $0.592^{* *}$ & $-0.415^{* *}$ & $-0.792^{* *}$ & - \\
\hline
\end{tabular}

${ }^{\star} p<0.05,{ }^{*} P<0.001, \alpha=$ Cronbach's alpha.

Table 2. Hierarchical regression analysis for variables predicting verbal aggressiveness.

\begin{tabular}{cccccc}
\hline Variables & $\mathrm{R}^{2}$ & $\Delta \mathrm{R}^{2}$ & $\mathrm{~B}$ & $\mathrm{SEB}$ & $\beta$ \\
\hline Step 1 & & & & & \\
Argumentativeness & 0.59 & & -1.14 & 0.03 & $-0.77^{* *}$ \\
Step 2 & & 0.10 & & & \\
Argumentativeness & & & -0.89 & 0.03 & $-0.60^{* *}$ \\
Mastery climate & & -0.22 & 0.04 & $-0.18^{* *}$ \\
Performance climate & & 0.21 & 0.03 & $0.20^{* *}$ \\
Total $\mathrm{R}^{2}$ & 0.47 & & & & \\
\hline
\end{tabular}

${ }^{*} p<0.05,{ }^{* *} P<0.001, \alpha=$ Cronbach's alpha.

Furthermore, mastery and performance climate were included in the second step. The first outcome indicated that the total variance of verbal aggressiveness explained by argumentativeness was $59 \%, F_{\text {cha }}(1,902)=1279.07, p<0.001$. The results from the second step showed that mastery and performance climate predicted for an additional $10 \%$ of verbal aggressiveness variance $F_{\text {cha }}(2,899)=$ $148.25, p<0.001$. In the final model all measures were statistically significant, concluding that argumentativeness $(\beta=-0.60, t=-28.02, p<0.001)$, mastery climate $(\beta=-0.18, t=-5.82, p<0.001)$ and performance climate $(\beta=0.20, t=$ $6.53, p<0.001)$ raised statistically significant verbal aggressiveness prediction. This pattern of results suggests that instructors' verbal aggressiveness is negatively predicted by argumentativeness which recorded a higher beta value, while mastery and performance climate contribute the least to that prediction.

Moreover two-way MANOVA, presented on "Table 3", was performed to examine differences existed in verbal aggressiveness, argumentativeness, motivational climate between schools' region and students' school level (primary, secondary and high school). The findings according to Wilks' $\lambda$ showed statistically significant multivariate effect on school level, $\lambda=0.69, F(8,1784)=46.11, p<$ 0.001 , schools' region, $\lambda=0.65, F(8,1784)=52.92, p<0.001$ and the interaction between school level and schools' region, $\lambda=0.79, \mathrm{~F}(12,2360)=18.85, p<$ 0.001 .

The examination of the univariate effects revealed significant effect of students' school level on verbal aggressiveness $F(2,895)=95.85, p<0.001, \eta^{2}=$ 
0.18 , argumentativeness $F(2,895)=108.07, p<0.001, \eta^{2}=.20$, mastery $F(2$, $895)=31.56, p<0.001, \eta^{2}=0.07$ and performance climate $F(2,895)=81.72, p<$ $0.001, \eta^{2}=0.15$. An examination of the mean scores indicated that secondary schools $(M=2.94, S D=1.21)$ proved to have higher score in verbal aggressiveness than high schools $(M=2.73, S D=1.22)$, as well as primary schools indicated higher score $(M=2.91, S D=1.16)$ compared to high schools. Concerning argumentativeness high schools presented the higher score $(M=2.63, S D=0.83)$ and secondary schools the lower $(M=2.38, S D=0.71)$. Furthermore, primary schools were rated by higher levels $(M=3.44, S D=1.00)$ of mastery climate, than high schools $(M=3.42, S D=0.96)$. Finally, students' from primary schools perceived that their instructors created performance climate in higher levels $(M$ $=3.26, S D=1.05)$ than the other school levels, while high schools showed the lower score $(M=2.61, S D=1.12)$ (“Table 3(a)").

Also, the examination of the univariate effects revealed significant effect of schools' region on verbal aggressiveness $F(2,895)=168.56, p<0.001, \eta^{2}=0.27$, argumentativeness $F(2,895)=107.92, p<0.001, \eta^{2}=0.19$ mastery climate $F(2$, $895)=122.42, p<0.001, \eta^{2}=0.22$ performance climate $F(2,895)=77.21, p<$ $0.001, \eta^{2}=0.15$. An examination of the mean scores indicated that urban schools presented higher levels $(M=3.17, S D=1.15$ and $M=2.93, S D=1.19)$ and rural schools the lower $(M=2.03, S D=0.70$ and $M=2.22, S D=0.85)$ on verbal aggressiveness and performance climate. Moreover, rural schools revealed the higher scores $(M=2.87, S D=0.83$ and $M=4.05, S D=0.57)$ and the urban the lower scores $(M=2.33, S D=0.68$ and $M=3.13, S D=1.03)$ on argumentativeness and mastery climate (“Table $3(\mathrm{~b})$ ").

Finally, the examination of the univariate effects presented significant effect of Table 3. (a) Students' school level differences; (b) Schools' region differences.

(a)

\begin{tabular}{|c|c|c|c|c|c|c|c|c|}
\hline \multirow{2}{*}{ Variables } & \multicolumn{2}{|c|}{ Primary schools } & \multicolumn{2}{|c|}{ Secondary schools } & \multicolumn{2}{|c|}{ High schools } & \multirow{2}{*}{$p$} & \multirow{2}{*}{$\begin{array}{c}\text { partial } \\
\eta^{2}\end{array}$} \\
\hline & $M$ & $S D$ & $M$ & $S D$ & $M$ & $S D$ & & \\
\hline Verbal aggressiveness & 2.91 & 1.16 & 2.94 & 1.12 & 2.73 & 1.22 & 0.001 & 0.18 \\
\hline Argumentativeness & 2.55 & 0.79 & 2.38 & 0.71 & 2.63 & 0.83 & 0.001 & 0.20 \\
\hline Mastery climate & 3.44 & 1.00 & 3.53 & 0.96 & 3.42 & 0.96 & 0.001 & 0.07 \\
\hline Performance climate & 3.26 & 1.05 & 2.64 & 1.10 & 2.61 & 1.12 & 0.001 & 0.15 \\
\hline
\end{tabular}

(b)

\begin{tabular}{cccccccccc}
\hline \multirow{2}{*}{ Variables } & \multicolumn{2}{c}{ Urban } & \multicolumn{2}{c}{ Semi-urban } & \multicolumn{2}{c}{ Rural } & & partial \\
\cline { 2 - 6 } & $M$ & $S D$ & $M$ & $S D$ & $M$ & $S D$ & & $\eta^{2}$ \\
\hline Verbal aggressiveness & 3.17 & 1.15 & 2.87 & 1.20 & 2.03 & 0.70 & 0.001 & 0.27 \\
Argumentativeness & 2.33 & 0.68 & 2.61 & 0.83 & 2.87 & 0.83 & 0.001 & 0.19 \\
Mastery climate & 3.13 & 1.03 & 3.60 & 0.85 & 4.05 & 0.57 & 0.001 & 0.22 \\
Performance climate & 2.93 & 1.19 & 2.90 & 1.07 & 2.22 & 0.85 & 0.001 & 0.15 \\
\hline
\end{tabular}


the interaction between school level and schools' region on verbal aggressiveness $F(3,895)=20.00, p<0.001, \eta^{2}=0.06$, argumentativeness $F(3,895)=31.86, p<$ $0.001, \eta^{2}=0.10$ mastery climate $F(3,895)=15.31, p<0.001, \eta^{2}=0.05$ performance climate $F(3,895)=6.01, p<0.001, \eta^{2}=0.02$. On verbal aggressiveness higher scores revealed the primary schools on urban areas $(M=4.31, S D=0.55)$, than the other school levels and the secondary schools on semi-urban $(M=3.38$, $S D=1.22)$ and rural regions $(M=2.18, S D=0.72)$. As far as argumentativeness is concerned higher scores on urban $(M=2.44, S D=0.73)$ and semi-urban $(M=$ $3.60, S D=0.60$ ) were presented by the high schools comparing to primary and to secondary schools, while primary schools showed the higher score on rural regions $(M=3.28, S D=0.75)$, than the other school levels. Furthermore, mastery climate on high $(M=3.30, S D=0.97)$ and secondary schools $(M=3.11, S D$ $=1.12$ ) from urban areas revealed the higher score compared to primary schools, also high schools on semi-urban regions $(M=4.03, S D=0.65)$ showed higher score than primary and then secondary schools. Finally, concerning perceived performance climate, on urban regions' primary schools higher score was revealed $(M=4.15, S D=0.72)$ than secondary and then high schools, as well as primary schools from semi-urban $(M=3.37, S D=0.79)$ and rural areas $(M=$ 2.52, $S D=0.95)$ presented the higher score than the other school levels.

Moreover one-way MANOVA, was performed to examine differences existed in argumentativeness and motivational climate between the perceived level of verbal aggressiveness (low, moderate and high). The findings according to Wilks' $\lambda$ showed statistically significant multivariate effect on argumentativeness, $\lambda=0.46, F(6,1796)=143.90, p<0.001$.

The examination of the univariate effects revealed significant effect of verbal aggressiveness on argumentativeness $F(2,900)=158.26, p<0.001, \eta^{2}=0.37$, mastery $F(2,900)=111.31, p<0.001, \eta^{2}=0.38$ and performance climate $F(2$, $900)=195.07, p<0.001, \eta^{2}=0.34$. An examination of the mean scores indicated that instructors who use low level of verbal aggressiveness proved to have higher score in argumentativeness $(M=2.95, S D=0.76)$ and mastery climate $(M=$ 3.93, $S D=0.57)$. Instructors' who show high level of verbal aggressiveness presented the higher score in performance climate $(M=3.78, S D=1.02)$.

Because of those differences, as "Table 4" displays, Univariate Analysis of Covarience (ANCOVA) was conducted with independent variable the perception of low, moderate or high verbal aggressiveness. The dependent variable consisted of performance climate and covariate was the variable of argumentativeness. Preliminary checks were conducted to ensure that there was no violation of the assumptions of normality, linearity, homogeneity of variances, ho-

Table 4. The results of ANCOVA for determining of effects of verbal aggressiveness on performance climate.

\begin{tabular}{ccccc}
\hline Variables & df & Mean square & $p$ & partial $\eta^{2}$ \\
\hline Verbal aggressiveness & 2 & 100.24 & 0.000 & 0.21 \\
\hline
\end{tabular}


mogeneity of regression slopes, and reliable measurement of the covariate.

After adjusting the covariate, there was significant interaction effect of verbal aggressiveness on performance climate $F(2,899)=120.16, p<0.001$, with a large effect size $\eta^{2}=0.21$. The adjusted means show that higher levels of performance climate come from high use of verbal aggressiveness $(M=3.78, S D=$ 1.02). The covariate argumentativeness, adjusted statistically significant the score of verbal aggressiveness for performance climate $F(1,899)=10.41, p<0.05$. The adjustment of argumentativeness decreased drastically the relationship power of verbal aggressiveness with performance climate, the initial $\eta^{2}=0.46$ decreased in $\eta^{2}=0.21$.

Two-way MANOVA, presented on “Table 5", was performed to examine differences existed in verbal aggressiveness, argumentativeness, motivational climate between students' gender and class. The findings according to Wilks' $\lambda$ showed statistically significant multivariate effect on gender, $\lambda=0.99, F(4,884)$ $=3.23, p<0.05$ and class, $\lambda=0.77, F(28,3189)=8.73, p<0.001$, but no significant interaction between them.

The examination of the univariate effects revealed significant effect of students' class on verbal aggressiveness $F(7,887)=5.39, p<0.001, \eta^{2}=0.04$, argumentativeness $F(7,887)=8.53, p<0.001, \eta^{2}=0.06$, mastery $F(7,887)=4.23$, $p<0.001, \eta^{2}=0.03$ and performance climate $F(7,887)=10.09, p<0.001, \eta^{2}=$ 0.07 . An examination of the mean scores indicated that $9^{\text {th }}$ grade $(M=3.22, S D=$ 0.88 ) proved to have higher score in verbal aggressiveness. Concerning argumentativeness $(M=2.73, S D=0.81)$ and mastery climate $(M=3.75, S D=0.88)$, $7^{\text {th }}$ grade presented the higher score. Finally, students' from $6^{\text {th }}$ grade perceived that their instructors created performance climate in higher levels $(M=3.27, S D$ $=1.05$ ).

Differences of verbal aggressiveness and argumentativeness between gender and class were assessed using a Multivariate Analysis of Covariance (MANCOVA). Mastery and performance climate were entered as covariates in the analysis. Results indicated that the covariates, mastery climate Wilks' $\lambda=0.904, F(2,884)=$ 46.97, $p<0.001$ and performance climate Wilks' $\lambda=0.953, F(2,884)=21.82, p$ $<0.001$, explained a statistically significant proportion of variance of verbal aggressiveness and argumentativeness. After the removal of covariates' main effect significant statistical differences existed in verbal aggressiveness and argumentativeness between classes Wilks' $\lambda=0.927, F(14,1768)=4.86, p<0.001$. Subse-

Table 5. The results of two-way MANCOVA for determining of effects of the perception of verbal aggressiveness and argumentativeness.

\begin{tabular}{ccccc}
\hline \multirow{2}{*}{ Variables } & \multicolumn{2}{c}{ Gender } & \multicolumn{2}{c}{ Class } \\
\cline { 2 - 5 } & F-value & $\eta^{2}$ & F-value & $\eta^{2}$ \\
\hline Verbal aggressiveness & 3.58 & 0.004 & $5.25^{\star *}$ & 0.040 \\
Argumentativeness & 0.28 & 0.000 & $9.39^{* *}$ & 0.069 \\
\hline
\end{tabular}

${ }^{*} p<0.05,{ }^{* *} P<0.001$. 
quent univariate analyses were computed for each dependent variable. Each covariate, mastery $F(1,885)=88.89, p<0.001$ and performance climate $F(1,885)$ $=36.44, p<0.001$, provided a significant adjustment to verbal aggressiveness. Also, mastery $F(1,885)=63.78, p<0.001$ and performance climate $F(1,885)=$ $4.11, p<0.05$, provided a significant adjustment to argumentativeness. Afterwards, differences emerged in class for the two dependent variables, verbal aggressiveness $F(7,885)=5.25, p<0.001$ and argumentativeness $F(7,885)=9.39$, $p<0.001$. The $8^{\text {th }}$ grade students indicated higher scores on verbal aggressiveness (adusted $M=3.16$ ), while $12^{\text {th }}$ grade students showed lower scores on verbal aggressiveness. Moreover, $12^{\text {th }}$ grade students indicated higher scores on argumentativeness (adusted $M=2.76$ ), while $9^{\text {th }}$ grade students presented higher scores on argumentativeness (adusted $M=2.20$ ). During the adjustment, students in $8^{\text {th }}$ and $12^{\text {th }}$ grade, as well as in $9^{\text {th }}$ and $12^{\text {th }}$ grade slightly decreased their difference in verbal aggressiveness and argumentativeness.

\section{Discussion and Challenges for Future Research}

The aim of this study was to: a) explore the relationship between perceived instructors' verbal aggressiveness, argumentativeness and motivational climate in physical education classes, b) investigate the influence of instructors' argumentativeness and motivational climate on their use of verbal aggressiveness, c) examine differences in verbal aggressiveness, argumentativeness and motivational climate between schools' region and students' school level (primary, secondary and high schools), as well as between gender and class, d) explore differences in verbal aggressiveness and argumentativeness between gender and class, using motivational climate as covariate, e) investigate differences in argumentativeness and motivational climate between low verbal aggressiveness, moderate and high verbal aggressiveness, $\mathrm{f}$ ) research the differences in performance climate between low, moderate and high verbal aggressiveness using argumentativeness as covariate.

The results of the study indicated that perceived instructors' verbal aggressiveness was positively related to performance climate, while was negatively related to argumentativeness and mastery climate. Furthermore, instructors' argumentativeness was positively related to mastery climate, while was negatively related to performance climate. Finally, there was a negative relationship between mastery climate and performance climate. The findings of the present study are in accordance with these of previous research indicating that instructors' verbal aggressiveness was negatively related to argumentativeness (Bekiari, 2017a; Infante \& Rancer, 1996; Syrmpas \& Bekiari, 2015). Furthermore, previous studies (Bekiari, 2016; Bekiari \& Syrmpas, 2015), argued that there is a positive relationship between verbal aggressiveness and performance climate, as well as a negative one with mastery climate. As it is also verified by Infante and Rancer (1996) verbal aggressiveness is attacking the interlocutor's personality while argumentativeness focuses on the statements about an issue, then arguably argu- 
mentativeness is positively related to mastery climate and negatively to performance climate. It is showed that verbally aggressive instructors may not have the ability to use arguments and they adopt a motivational climate focused on performance but not individual growth, whilst argumentative instructors promote thinking, effort, self-confidence and learning (Bekiari, 2016; Bekiari, 2012; 2014; Bekiari \& Hasanagas, 2015; Bekiari \& Syrmpas, 2015; Bekiari, Perkos, \& Gerodimos, 2015; Hamilton \& Hample, 2011; Hasanagas \& Bekiari, 2015; Hassandra, Bekiari, \& Sakellariou, 2007; Manoli \& Bekiari, 2015; Myers, 2002; Myers \& Rocca, 2001; Syrmpas \& Bekiari, 2015).

In this study it was, also, revealed that instructors' verbal aggressiveness was influenced by their use of argumentativeness and the created motivational climate. The trait of argumentativeness emerged as the most important negative predictor of verbal aggressiveness, while motivational climate contribute the least to that predictor. Low skills on argumentativeness lead to inadequacy in debating, consequently the immediate reaction of such an instructor is to attack verbally to students (Infante et al., 1984). Moreover, a reasonable explanation of this finding could be the fact that the created classroom environment induces the adoption of a specific behavior by the instructor. For instance in physical education context, efficacy and accomplishments consist prevalent goals, hence instructors conduce to apply a verbally aggressive behavior due to tensity heightened by such conditions.

The findings of this research suggest that secondary and primary school students perceive their instructors as more verbal aggressive compared to high school students who perceive them as more argumentative and less verbal aggressive. These results parallel Roach's (1992) research. A reasonable explanation for this finding could be the fact that students in high schools are more mature and are more capable of getting in a productive conversation with their instructors by using arguments. On the other hand in primary and secondary schools, instructors' approach is considered verbally aggressive because students at those ages are quite intractable, less cooperative and less compliant, hence instructors are endeavoring to reinstate discipline through verbal aggressiveness, and also the lessons' concept are more knowledge-based, thus instructors may be less inclined to argumentativeness. In addition, younger students have not the abilities to debate through arguments, hence argumentativeness is not promoted as a learning activity, contrary to students from higher grade level. Furthermore, primary school students ranked their instructors higher in mastery climate, compared to high school students. Also, performance climate was presented at a higher level in primary schools, compared to secondary and high schools, where the latest reported the lower level on performance climate, findings consistent with the research of Theodosiou, Mantis, and Papaioannou (2008). Moreover, high scores both of mastery and performance climate are revealed in primary schools and this finding is in accordance with Deliligka, Syrmpas, and Bekiari (2018) where it was found that both conditions of motivational climate can be 
derived in a PE lesson as instructors in some cases tend to create a mastery climate, while they point out students' performance in other circumstances. In addition, Taking into consideration that instructors in primary schools tend to use traditional competitive games (Konstantinidou, Michalopoulou, Aggelousis, \& Kourtesis, 2011) it can be assumed that may foster students' perception of performance climate in PE lesson. Furthermore, urban schools presented higher levels on verbal aggressiveness and performance climate, while rural schools the lower. Also, concerning argumentativeness and mastery climate rural schools revealed the higher scores and the urban the lower. This finding may be interpreted by the fact that in urban areas the students are numerous and the relationship between them and their instructors is more impersonal, consequently instructors' verbal aggressiveness is enhanced in order to be imposed on their students. Furthermore, in urban areas competition is heightened because of peers', parents', other schools' pressure and the demands are increased as well, so there is an emphasis on performance and exceeding others. Whereas, in rural areas such tension is eliminated due to diverse conditions, so the goals are emphasized effectively and are directed through discussion and stating opinions, cooperative learning and effort. Moreover, primary schools on urban areas and secondary schools on semi-urban, as well as on rural regions revealed higher scores on verbal aggressiveness. As far as argumentativeness is concerned, higher scores on urban and semi-urban were presented by high schools, while primary schools on rural regions showed the higher score. Furthermore, mastery climate on high and secondary schools from urban areas revealed the higher score compared to primary schools, and high schools on semi-urban regions showed higher score than primary and then secondary schools. Finally, concerning perceived performance climate, on urban regions' primary schools higher score was revealed than secondary, and then high schools as well as primary schools from semi-urban and rural areas presented the higher score than the other school levels. In similar direction the findings of Bekiari (2014), Bekiari, Kokaridas, and Sakellariou (2006), Bekiari and Petanidis (2016) have revealed that students from suburban and rural areas presented great effort and interest, while students from urban areas had stress, pressure, lack of interest during the course of physical education.

The results of this study indicated no differences on verbal aggressiveness, argumentativeness and motivational climate between students' gender. This finding is in accordance with the research of Bekiari and Balla (2017), Bekiari, Digelidis, and Sakellariou (2006), Theodosiou, Mantis, and Papaioannou (2008). However, the finding in this specific case is in contrast with Bekiari (2014), Bekiari (2017b), Bekiari et al. (2015), Bekiari and Petanidis (2016), Bekiari and Syrmpas (2015), Infante and Gorden (1989). Furthermore, $9^{\text {th }}$ grade proved to have higher score in verbal aggressiveness, $7^{\text {th }}$ grade in argumentativeness and mastery climate. Finally, students from $6^{\text {th }}$ grade perceived that their instructors created performance climate in higher levels and relational findings have been 
mentioned in other studies as well (Bekiari \& Tsiana, 2016; Bekiari \& Pylarinou, 2017).

Results of the multivariate analysis of covariance showed that mastery and performance climate significantly contributed to the explanation of those differences, confirming the general assumption that there is a relation between the learning environmental factors and perceived instructors' behavior. This was also highlighted from correlation analysis where all variables demonstrated significant relations. As Treasure and Roberts (1995) indicated, the preponderant mastery or performance climate affects directly behavioral characteristics, which get in alignment with the prevalent motivational climate. Interestingly, it can be justified that through motivational climate created in PE lessons, instructors' authority role is emphasized. Consequently, the goals of a mastery climate may promote a communicative and argumentative instructor. On the other hand, in a performance climate the instructors' behavior can be interpreted as aggressive, because verbally aggressive individuals are considered less responsive (Martin \& Anderson, 1996; Myers, 1998), less cognitively and communicatively flexible (Martin, Anderson, \& Thweatt, 1998), and less likely to engage in verbal praise (Wigley, Pohl, \& Watt, 1989), thus causing negative effects on students' affective learning. These findings not only corroborate the claims advanced by Wrench and Punyanunt-Carter (2005), but support the growing amount of research that demonstrates how verbal aggressiveness has a negative impact on the learning environment.

The findings of this study reveal that differences exist between the levels of verbal aggressiveness, concerning argumentativeness and motivational climate. Particularly, students reported that instructors who use low level of verbal aggressiveness proved to have higher score in argumentativeness and mastery climate. Also, high level of verbal aggressiveness was presented in performance climate. Aggressive communicational traits such as verbal aggressiveness and argumentativeness, coincide on a person's behavior as has been verified in other studies as well (Edwards \& Myers, 2007; Infante et al., 1984; Infante et al., 1994; Infante \& Rancer, 1993; Kim \& Yang, 2013; Myers, 2002). Similarly, the findings of previous studies suggested that there are five communicational PE teachers' profiles and more precisely, "high argumentativeness-low verbal aggressiveness" "moderate argumentativeness and verbal aggressiveness", "moderate argumentativeness-low verbal aggressiveness", "low argumentativeness-high verbal aggressiveness", "low argumentativeness-moderate verbal aggressiveness" (Deliligka et al., 2017; Infante \& Rancer, 1982; 1996). According to the profiles when instructors are capable of arguing, they are less likely to expose a verbally aggressive behavior (Bekiari, 2016; Infante et al., 1984; Infante \& Rancer, 1996; Syrmpas \& Bekiari, 2015). Moreover, it can be concluded that instructors' usage of verbal aggressiveness, does not lead to mastery motivational climate and also the outcome is negative for their students (Martin, Rocca, Cayanus, \& Weber, 2009). Taking under consideration that verbal aggressiveness attacks the interlocutor's 
self-perception (Infante \& Wingley, 1986), it is expected that students do not have positive feelings about the created motivational climate (Bekiari, 2012). As results from previous study has shown, verbal aggressiveness leads to an increased anxiety and is strictly related to autocratic style of teaching (Bekiari, 2014).

Finally, in this study it was revealed the role or argumentativeness in PE class, as it was found to be a significant covariate of verbal aggressiveness on performance climate. Interestingly, students' perceptions and affective learning reflections confirm the assertions that high argumentative are more task oriented and socially experienced (Infante, 1981; Onyekwere, Rubin, \& Infante, 1991; Roach, 1995). The positive outcomes derived from instructors' argumentative behavior are numerous. It contributes to the accomplishment of students' personal goals, heightened cognitive motivation, promoting the learning process, and improved interpersonal relations at class level, as instructors facilitate students by arguing (Infante \& Rancer, 1996; Myers, 1998; Myers, 2002; Rancer \& Infante, 1985).

There are a few limitations that should be mentioned in this research. First and foremost, participants belonged to a restricted area and so students from a wider spread of regions in Greece should be recruited in a similar future study in order to increase findings' generalization. Furthermore, a more balanced sampling between urban, semi-urban and rural participants could take place. Another aspect is the fact that relations and influences are predominant in the results and causality is not directly supported. In addition, other factors have not been taken into account, such as possible students' and instructors' cultural differences and instructors' teaching experience. Implications for further research could lead to in depth interviews with students in order to add any additional influential factors and to evaluate the results from a qualitative approach. Moreover, peer and parents influence could be included in motivational climate. Finally, there is limited research of social network analysis in the field of argumentativeness and motivational climate.

\section{Conclusion}

The present study concludes that verbal aggressiveness consists a destructive communicational trait, while argumentativeness is a constructive one as has been proved to various previous studies as well (Avtgis et al., 2008; Infante, 1988; Infante \& Rancer, 1996; Martin \& Myers, 2006; Rancer \& Avtgis, 2014). Students' perceptions about verbal aggressiveness as an improper classroom behavior, justify the fact that they pay attention to classroom environment's relevance for the performance climate. As had been confirmed, verbal aggressiveness was positively related to performance climate, whereas argumentativeness was positively related to mastery climate. Additionally, the preponderant mastery or performance climate affects directly behavioral characteristics. The results provided valuable knowledge, so that instructors who teach lower grades and in urban areas should tend to be more argumentative and create a mastery climate. 
The findings of the study arouse an awareness of the relations among instructors' aggressive behavior and motivational climate. Specifically, the afore-mentioned results can effectively incite introspective reflection, in order for instructors to maintain positive adaptive behavior and a supportive learning environment, because the majority of them may be unaware of the communication they are engaging in during class. If they can become more aware of these behaviors and the perceptions they are creating in the students' minds, then positive outcomes will be enhanced in the learning process.

\section{References}

Aloia, L. S., \& Solomon, D. H. (2016). Emotions Associated with Verbal Aggression Expression and Suppression. Western Journal of Communication, 80, 3-20. http://dx.doi.org/10.1080/10570314.2014.943428

Ames, C. (1992a). Classrooms: Goals, Structures, and Student Motivation. Journal of Educational Psychology, 84, 261-271. http://dx.doi.org/10.1037/0022-0663.84.3.261

Ames, C. (1992b). Achievement Goals, Motivational Climate, and Motivational Processes. In G. C. Roberts (Eds.), Motivation in Sport and Exercise (pp. 161-176). Champaign, IL: Human Kinetics.

Ames, C., \& Archer, J. (1988). Achievement Goals in the Classroom: Students' Learning Strategies and motivation processes. Journal of Educational Psychology, 80, 260-267. http://dx.doi.org/10.1037/0022-0663.80.3.260

Atkins, M. R., Johnson, D. M., Force, E. C., \& Petrie, T. A. (2015). Peers, Parents, and Coaches, Oh My! The Relation of the Motivational Climate to Boys' Intention to Continue in Sport. Psychology of Sport and Exercise, 16, 170-180. http://dx.doi.org/10.1016/j.psychsport.2014.10.008

Avtgis, T. A., Rancer, A. S., Kanjeva, P. A., \& Chory, R. M. (2008). Argumentative and Aggressive Communication in Bulgaria: Testing for Conceptual and Methodological Equivalence. Journal of Intercultural Communication Research, 37, 17-24. https://doi.org/10.1080/17475750802077354

Avtgis, T., \& Rancer, A. S. (2010). Arguments, Aggression, and Conflict: New Directions in Theory and Research. New York: Routledge.

Bekiari, A. \& Spanou, K. (2018). Machiavellianism in Universities: Perceiving Exploitation in Student Networks. Social Networking, 7, 19-31. http://dx.doi.org/10.4236/sn.2018.71002

Bekiari, A. (2012). Perceptions of Instructors' Verbal Aggressiveness and Physical Education Students' Affective Learning. Perceptual and Motor Skills, 115, 325-335. http://dx.doi.org/10.2466/06.11.16.PMS.115.4.325-335

Bekiari, A. (2014). Verbal Aggressiveness and Leadership Style of Sports Instructors and their Relationship with Athletes' Intrinsic Motivation. Creative Education, 5, 114-121. http://dx.doi.org/10.4236/ce.2014.52018

Bekiari, A. (2016). Insights into Instructors' Verbal Aggressiveness and Students' Machiavellianism through Leadership Style and Motivational Climate. European Scientific Journal, 12, 90-110. http://dx.doi.org/10.19044/esj.2016.v12n25p90

Bekiari, A. (2017a). Exploring Relations between Instructors' Verbal Aggressiveness and Argumentativeness and Students' Fair Play Behaviours and Machiavellianism. International Journal of Physical Education, 54, 26-39.

Bekiari, A. (2017b). Verbally Aggressive Instructors and Machiavellian Students: Is the 
Socio-Communicative Style an Over-Bridging? Psychology, 8, 1437-1454. http://dx.doi:10.4236/psych.2017.810095

Bekiari, A., \& Balla, K. (2017). Instructors and Students Relations: Argumentativeness, Leadership and Goal Orientations. Open Journal of Social Sciences, 5, 128-143. http://dx.doi.org/10.4236/jss.2017.57009

Bekiari, A., \& Digelidis, N. (2015). Measuring Verbal Aggressiveness in Sport and Education. International Journal of Physical Education, 52, 12-21.

Bekiari, A., \& Hasanagas, N. (2015). Verbal Aggressiveness Exploration through Complete Social Network Analysis: Using Physical Education Students' Class as an Illustration. International Journal of Social Science Studies, 3, 30-49. http://dx.doi.org/10.11114/ijsss.v3i3.729

Bekiari, A., \& Hasanagas, N. (2016a). Sociological Insights in the Education System: "Unlocking" the Power Relations. Thessaloniki: Afoi Kyriakidi Editions S.A.

Bekiari, A., \& Hasanagas, N. (2016b). "Educating” in Physical Education. Theoretical Approaches and Practical Inquiries. Thessaloniki: Afoi Kyriakidi Editions S.A.

Bekiari, A., \& Hasanagas, N. (2016c). Suggesting Indicators of Superficiality and Purity in Verbal Aggressiveness: An Application in Adult Education Class Networks of Prisoners. Open Journal of Social Sciences, 4, 279-292. https://doi.org/10.4236/jss.2016.43035

Bekiari, A., \& Manoli, P. (2016). EFL Teacher Verbal Aggressiveness and Argumentativeness and Student Socio-Affective Strategy Use and Affective Learning: Exploring Possible Associations. Journal of Teacher Education and Educators, 5, 154-171.

Bekiari, A., \& Ntakou, V. (2018). Insights to Argumentativeness in Relation to Leadership Style and Job Satisfaction: Using Employees' Sport Organizations as an Illustration. Open Journal of Leadership. (In Press)

Bekiari, A., \& Pachi, V. (2017). Insights into Bullying and Verbal Aggressiveness through Social Network Analysis. Journal of Computer and Communications, 5, 79-101. https://doi.org/10.4236/jcc.2017.59006

Bekiari, A., \& Petanidis, D. (2016). Exploring Teachers' Verbal Aggressiveness through Interpersonal Attraction and Students' Intrinsic Motivation. Open Journal of Social Sciences, 4, 72-85. http://dx.doi.org/10.4236/jss.2016.412007

Bekiari, A., \& Pylarinou, M. (2017). Instructor Argumentativeness and Socio-Communicative Style and Student Discipline: Using Physical Education Students' Class as an Illustration. Open Journal of Social Sciences, 5, 122-136. http://dx.doi.org/10.4236/jss.2017.53011

Bekiari, A., \& Sakellariou, K. (2003). Perceived Instructor Verbal Aggressiveness and Student State Learning in Physical Education. Italian Journal of Sport Sciences, 1, 251256.

Bekiari, A., \& Spyropoulou, S. (2016). Exploration of Verbal Aggressiveness and Interpersonal Attraction through Social Network Analysis: Using University Physical Education Class as an Illustration. Open Journal of Social Sciences, 4, 145-155. http://dx.doi.org/10.4236/jss.2016.46016

Bekiari, A., \& Syrmpas, I. (2015). Coaches' Verbal Aggressiveness and Motivational Climate as Predictors of Athletes' Satisfaction. British Journal of Education, Society \& Behavioural Science, 9, 318-329. http://dx.doi:10.9734/BJESBS/2015/17757

Bekiari, A., \& Tsaggopoulou, T. (2016). Verbal Aggressiveness and Affective Learning in Physical Education. Advances in Physical Education, 6, 406-418. http://dx.doi.org/10.4236/ape.2016.64041

Bekiari, A., \& Tsiana, I. (2016). Exploring Instructors' Verbal Aggressiveness and Stu- 
dents' Personal Orientations and Reasons of Discipline in Physical Education Class. Advances in Physical Education, 6, 158-168. http://dx.doi.org/10.4236/ape.2016.63018

Bekiari, A., Deliligka, S., \& Hasanagas, N. (2017). Analysing Networks of Verbal Aggressiveness and Motivation. Psychology, 8, 495-515.

http://dx.doi.org/10.4236/psych.2017.83031

Bekiari, A., Deliligka, S., \& Koustelios, A. (2016). Examining Relations of Aggressive Communication in Social Networks. Social Networking, 6, 38-52. http://dx.doi.org/10.4236/sn.2017.61003

Bekiari, A., Digelidis, N., \& Sakellariou, K. (2006). Perceived Verbal Aggressiveness of Coaches in Volleyball and Basketball: A Preliminary Study. Psychological Reports, 103, 526-530. http://dx.doi:10.2466/PMS.103.2.526-530

Bekiari, A., Kokaridas, D., \& Sakellariou, K. (2005). Verbal Aggressiveness of Physical Education Teachers and Students' Self-Reports of Behaviour. Psychological Reports, 96, 493-498. http://dx.doi.org/10.2466/pr0.96.2.493-498

Bekiari, A., Kokaridas, D., \& Sakellariou, K. (2006). Associations of Students' Self-Reports of Their Teacher's Verbal Aggression, Intrinsic Motivation, and Perceptions of Reasons for Discipline in Greek Physical Education Classes. Psychological Reports, 98, 451-461. http://dx.doi.org/10.2466/PR0.98.2.451-461

Bekiari, A., Koustelios, A., \& Sakellariou, K. (2000). Instructors' Verbal Aggressiveness from Universities in Greece. Studi e Ricerche, 5, 225-232.

Bekiari, A., Nikolaidou, Z., \& Hasanagas, N. (2017). Typology of Motivation and Aggression on the Basis of Social Network Variables: Examples of Complementary and Nested Behavioral Types through Conventional Statistics. Social Networking, 6, 135-147.

https://doi.org/10.4236/sn.2017.62008

Bekiari, A., Pachi, V., \& Hasanagas, N. (2017). Investigating Bullying Determinants and Typologies with Social Network Analysis. Journal of Computer and Communications, 5, 11-27. https://doi.org/10.4236/jcc.2017.57002

Bekiari, A., Patsiaouras, A., Kokaridas, D., \& Sakellariou, K. (2006). Verbal Aggressiveness and State Anxiety of Volleyball Players and Coaches. Psychological Reports, 99, 630-634. https://doi.org/10.2466/pr0.99.2.630-634

Bekiari, A., Perkos, S., \& Gerodimos, V. (2015). Verbal Aggression in Basketball: Perceived Coach Use and Athlete Intrinsic and Extrinsic Motivation. Journal of Physical Education and Sport, 15, 96-102. http://dx.doi:10.7752/jpes.2015.01016

Beltman, S., \& Volet, S. (2007). Exploring the Complex and Dynamic Nature of Sustained Motivation. European Psychologist, 12, 314-323. http://dx.doi.org/10.1027/1016-9040.12.4.314

Bengoechea, E. G., \& Strean, W. B. (2007). On the Interpersonal Context of Adolescents' Sport Motivation. Psychology of sport and exercise, 8, 195-217. http://dx.doi.org/10.1016/j.psychsport.2006.03.004

Bortoli, L., Bertollo, M., Vitali, F., Filho, E., \& Robazza, C. (2015). The Effects of Motivational Climate Interventions on Psychobiosocial States in High School Physical Education. Research Quarterly for Exercise and Sport, 86, 196-204.

http://dx.doi.org/10.1080/02701367.2014.999189

Braithwaite, R., Spray, C. M., \& Warburton, V. E. (2011). Motivational Climate Interventions in Physical Education: A Meta-Analysis. Psychology of Sport and Exercise, 12, 628-638. http://dx.doi.org/10.1016/j.psychsport.2011.06.005

Bryan, C. L., \& Solmon, M. A. (2012). Student Motivation in Physical Education and Engage-ment in Physical Activity. Journal of Sport Behavior, 35, 267. 
Coyne, S. M., \& Archer, J. (2004). Indirect Aggression in the Media: A Content Analysis of British Television Programs. Aggressive Behavior, 30, 254-271. https://doi.org/10.1002/ab.20022

Cumming, S. P., Smoll, F. L., Smith, R. E., \& Grossbard, J. R. (2007). Is Winning Everything? The Relative Contributions of Motivational Climate and Won-Lost Percentage in Youth Sports. Journal of Applied Sport Psychology, 19, 322-336. http://dx.doi.org/10.1080/10413200701342640

Cunningham, G. B., \& Xiang, P. (2008). Testing the Mediating Role of Perceived Motivational Climate in the Relationship between Achievement Goals and Satisfaction: Are These Relationships Invariant across Sex? Journal of Teaching in Physical Education, 27, 192-204. http://dx.doi.org/10.1123/jtpe.27.2.192

Deliligka, S., Bekiari, A., \& Syrmpas, I. (2017). Verbal Aggressiveness and Argumentativeness in Physical Education: Perceptions of Teachers and Students in Qualitative and Quantitative Exploration. Psychology, 8, 1693-1717.

http://dx.doi.org/10.4236/psych.2017.811112

Deliligka, S., Syrmpas, I., \& Bekiari, A. (2018). The Motivational Climate in the PE Context through the Perspective of Teachers and Students. The Physical Educator. (Forthcoming)

Duda, J. L., \& Ntoumanis, N. (2005). After-School Sport for Children: Implications of a Task-Involving Motivational Climate. In J. L. Mahoney, J. Eccles, and R. Larson (Eds.), Organized Activities as Contexts of Development: Extracurricular Activities, After-School and Community Programs, Lawrence Erlbaum Publishers, 311-330.

Edwards, C., \& Myers, S. A. (2007). Perceived Instructor Credibility as a Function of Instructor Aggressive Communication. Communication Research Reports, 24, 47-53. http://dx.doi.org/10.1080/08824090601128141

Goodboy, A. K., \& Myers, S. A. (2012). Instructional Dissent as an Expression of Students' Verbal Aggressiveness and Argumentativeness Traits. Communication Education, 61, 448-458. http://dx.doi.org/10.1080/03634523.2012.699635

Granero-Gallegos, A., Baena-Extremera, A., Gómez-López, M., \& Abraldes, J. A. (2014). Importance of Physical Education: Motivation and Motivational Climate. ProcediaSocial and Behavioral Sciences, 132, 364-370. http://dx.doi.org/10.1016/j.sbspro.2014.04.323

Hamilton, M., \& Hample, D. (2011). Testing Hierarchical Models of Argumentativeness and Verbal Aggressiveness. Communication Methods and Measures, 5, 250-273. http://dx.doi.org/10.1080/19312458.2011.596991

Hasanagas, N., \& Bekiari, A. (2015). Depicting Determinants and Effects of Intimacy and Verbal Aggressiveness Target through Social Network Analysis. Sociology Mind, 5, 162-175. http://dx.doi.org/10.4236/sm.2015.53015

Hasanagas, N., \& Bekiari, A. (2017a). An Exploration of the Relation between Hunting and Aggressiveness: Using Inmates Networks at Prison Secondary School as an Illustration. Social Networking, 6, 19-37. https://doi.org/10.4236/sn.2017.61002

Hasanagas, N., \& Bekiari, A. (2017b). Relation of Attitudes toward Environment and Animals with Social and Criminal-Aggressive Profile of Adult Inmates in School Classes of a Correctional Facility. International Journal of Social Research, 1-12.

Hasanagas, N., Bekiari, A., \& Vasilos, P. (2017). Friendliness to Animals and Verbal Aggressiveness to People: Using Prison Inmates Education Networks as an Illustration. Social Networking, 6, 224-238. https://doi.org/10.4236/sn.2017.63015

Hassandra, M., Bekiari, A., \& Sakellariou, K. (2007). Physical Education Teacher's Verbal Aggression and Student's Fair Play Behaviors. The Physical Educator, 64, 94-101. 
Hrázská, G. Z. (2011). Research of Aggression in the Relationship among Athletes in Figure Skating and Their Coaches. Journal of Human Sport and Exercise, 7, S1-S7. http://dx.doi.org/10.4100/jhse.2012.7.Proc1.01

Infante, D. A. (1981). Trait Argumentativeness as a Predictor of Communicative Behavior in Situations Requiring Argument. Central States Speech Journal, 32, 265-272. https://doi.org/10.1080/10510978109368105

Infante, D. A. (1987). Aggressiveness. In J. C. McCroskey, \& J. A. Daly (Eds.), Personality and Interpersonal Communication (pp. 157-192). Newbury Park, CA: Sage.

Infante, D. A. (1988). Arguing Constructively. Prospect Heights, IL: Waveland Press.

Infante, D. A. (1995). Teaching Students to Understand and Control Verbal Aggression. Communication Education, 44, 51-63. http://dx.doi.org/10.1080/03634529509378997

Infante, D. A., \& Gorden, W. I. (1989). Argumentativeness and Affirming Communicator Style as Predictors of Satisfaction/Dissatisfaction with Subordinates. Communication Quarterly, 37, 81-90. https://doi.org/10.1080/01463378909385529

Infante, D. A., \& Rancer, A. S. (1982). A Conceptualization and Measure of Argumentativeness. Journal of Personality Assessment, 46, 72-80. http://dx.doi.org/10.1207/s15327752jpa4601_13

Infante, D. A., \& Rancer, A. S. (1993). Relations between Argumentative Motivation, and Advocacy and Refutation on Controversial Issues. Communication Quarterly, 41, 415426. http://dx.doi.org/10.1080/01463379309369902

Infante, D. A., \& Rancer, A. S. (1996). Argumentativeness and Verbal Aggressiveness: A Review of Recent Theory and Research. Annals of the International Communication Association, 19, 319-352. http://dx.doi.org/10.1080/23808985.1996.11678934

Infante, D. A., \& Wigley III, C. J. (1986). Verbal Aggressiveness: An Interpersonal Model and Measure. Communications Monographs, 53, 61-69.

http://dx.doi.org/10.1080/03637758609376126

Infante, D. A., Myers, S. A., \& Buerkel, R. A. (1994). Argument and Verbal Aggression in Constructive and Destructive Family and Organizational Disagreements. Western Journal of Communication (Includes Communication Reports), 58, 73-84. http://dx.doi.org/10.1080/10570319409374488

Infante, D. A., Riddle, B. L., Horvath, C. L., \& Tumlin, S. A. (1992). Verbal aggressiveness: Messages and reasons. Communication Quarterly, 40, 116-126. http://dx.doi.org/10.1080/01463379209369827

Infante, D. A., Sabourin, T. C., Rudd, J. E., \& Shannon, E. A. (1990). Verbal Aggression in Violent and Nonviolent Marital Disputes. Communication Quarterly, 38, 361-371. http://dx.doi.org/10.1080/01463379009369773

Infante, D. A., Trebing, J. D., Shepherd, P. E., \& Seeds, D. E. (1984). The Relationship of Argumentativeness to Verbal Aggression. Southern Speech Communication Journal, 50, 67-77. http://dx.doi.org/10.1080/10417948409372622

Johnson, A. J., Becker, J. A., Wigley, S., Haigh, M. M., \& Craig, E. A. (2007). Reported Argumentativeness and Verbal Aggressiveness Levels: The Influence of Type of Argument. Communication Studies, 58, 189-205.

http://dx.doi.org/10.1080/10510970701341154

Kavussanu, M., \& Harnisch, D. L. (2000). Self-Esteem in Children: Do Goal Orientations Matter? British Journal of Educational Psychology, 70, 229-242.

http://dx.doi.org/10.1348/000709900158074

Kavussanu, M., \& Roberts, G. C. (1998). Motivation in Physical Activity Contexts: The Relationship of Perceived Motivational Climate to Intrinsic Motivation and Self-Effi- 
cacy. Journal of Sport and Exercise Psychology, 20, 264-280.

http://dx.doi.org/10.1123/jsep.20.3.264

Keegan, R. J., Harwood, C. G., Spray, C. M., \& Lavallee, D. E. (2009). A Qualitative Investigation Exploring the Motivational Climate in Early Career Sports Participants: Coach, Parent and Peer Influences on Sport Motivation. Psychology of Sport and Exercise, 10, 361-372. http://dx.doi.org/10.1016/j.psychsport.2008.12.003

Keegan, R., Spray, C., Harwood, C., \& Lavallee, D. (2010). The Motivational Atmosphere in Youth Sport: Coach, Parent, and Peer Influences on Motivation in Specializing Sport Participants. Journal of Applied Sport Psychology, 22, 87-105. http://dx.doi.org/10.1080/10413200903421267

Kim, Y., \& Yang, J. (2013). Impact of Chemyeon on Koreans' Verbal Aggressiveness and Argumentativeness. Korea Journal, 53, 48-77.

Konstantinidou, E., Michalopoulou, E., Aggelousis, N., \& Kourtesis, T. (2011). Creativity in Elementary Physical Education: A Qualitative Approach of Teachers Perceptions. Inquiries in Sport \& Physical Education, 9, 84-100.

Le Bars, H., Gernigon, C., \& Ninot, G. (2009). Personal and Contextual Determinants of Elite Young Athletes' Persistence or Dropping out over Time. Scandinavian Journal of Medicine \& Science in Sports, 19, 274-285. http://dx.doi.org/10.1111/j.1600-0838.2008.00786.x

Liukkonen, J., Barkoukis, V., Watt, A., \& Jaakkola, T. (2010). Motivational Climate and Students' Emotional Experiences and Effort in Physical Education. The Journal of Educational Research, 103, 295-308. http://dx.doi.org/10.1080/00220670903383044

Maehr, M. L., \& Nicholls, J. G. (1980). Culture and achievement Motivation: A Second look. In N. Warren (Eds.), Studies in Cross-Cultural Psychology (Vol. 2, pp. 221-267). New York: Academic Press.

Manoli, P., \& Bekiari, A. (2015). EFL Teachers' Verbal Aggressiveness and Students' Intrinsic Motivation and Social-Affective Strategy Use: Investigating Possible Relations. Advances in Research, 5, 1-13. http://dx.doi.org/10.9734/AIR/2015/19692

Martin, M. M., \& Anderson, C. M. (1996). Argumentativeness and Verbal Aggressiveness. Journal of Social Behavior and Personality, 11, 547-554.

Martin, M. M., Anderson, C. A., \& Thweatt, K. S. (1998). Aggressive Communication Traits and Their Relationships with the Cognitive Flexibility Scale and the Communication Flexibility Scale. Journal of Social Behavior and Personality, 13, 531-540.

Martin, M. M., Anderson, C. M., \& Horvath, C. L. (1996). Feelings about Verbal Aggression: Justifications for Sending and Hurt from Receiving Verbally Aggressive Messages. Communication Research Reports, 13, 19-26.

http://dx.doi.org/10.1080/08824099609362066

Martin, M. M., Rocca, K. A., Cayanus, J. L., \& Weber, K. (2009). Relationship between Coaches' Use of Behavor Alteration Techniques and Verbal Aggression on Athletes' Motivation and Affect. Journal of Sport Behavior, 32, 227-241.

Mazer, J. P., \& Stowe, S. A. (2016). Can Teacher Immediacy Reduce the Impact of Verbal Aggressiveness? Examining Effects on Student Outcomes and Perceptions of Teacher Credibility. Western Journal of Communication, 80, 21-37. http://dx.doi.org/10.1080/10570314.2014.943421

Mouratidis, A., Vansteenkiste, M., Lens, W., \& Auweele, Y. V. (2009). Beyond Positive and Negative Affect: Achievement Goals and Discrete Emotions in the Elementary Physical Education Classroom. Psychology of Sport and Exercise, 10, 336-343. https://doi.org/10.1016/j.psychsport.2008.11.004 
Murcia, J. A. M., Camacho, A. S., \& Rodríguez, J. M. M. (2008). Prognostic of the Perceived Competence through Motivation in Practitioners of Physical Exercise. Fitness and Performance Journal, 7, 357-365. http://dx.doi.org/10.3900/fpj.7.6.357.e

Myers, S. A. (1998). Instructor Socio-Communicative Style, Argumentativeness, and Verbal Aggressiveness in the College Classroom. Communication Research Reports, 15, 141-150. http://dx.doi.org/10.1080/08824099809362108

Myers, S. A. (2002). Perceived Aggressive Instructor Communication and Student State Motivation, Learning and Satisfaction. Communication Reports, 15, 113-121. http://dx.doi.org/10.1080/08934210209367758

Myers, S. A., \& Martin, M. M. (2006). Students' Communication Traits and Their Outof-Class Communication with Their Instructors. Communication Research Reports, 23, 283-289. https://doi.org/10.1080/08824090600962599

Myers, S. A., \& Rocca, K. A. (2000). The Relationship between Perceived Instructor Communicator Style, Argumentativeness, and Verbal Aggressiveness. Communication Research Reports, 17, 1-12. http://dx.doi.org/10.1080/08824090009388745

Myers, S. A., \& Rocca, K. A. (2001). Perceived Instructor Argumentativeness and Verbal Aggressiveness in the College Classroom: Effects on Student Perceptions of Climate, Apprehension, and State Motivation. Western Journal of Communication (Includes Communication Reports), 65, 113-137. http://dx.doi.org/10.1080/10570310109374696

Myers, S. A., Brann, M., \& Martin, M. M. (2013). Identifying the Content and Topics of Instructor Use of Verbally Aggressive Messages. Communication Research Reports, 30, 252-258. http://dx.doi.org/10.1080/08824096.2013.806260

Myers, S. A., Edwards, C., Wahl, S. T., \& Martin, M. M. (2007). The Relationship between Perceived Instructor Aggressive Communication and College Student Involvement. Communication Education, 56, 495-508. http://dx.doi.org/10.1080/03634520701466398

Nerstad, C. G., Roberts, G. C., \& Richardsen, A. M. (2013). Achieving Success at Work: Development and Validation of the Motivational Climate at Work Questionnaire (MCWQ). Journal of Applied Social Psychology, 43, 2231-2250.

http://dx.doi.org/10.1111/jasp.12174

Neuman, J. H., \& Baron, R. A. (1997). Aggression in the Workplace. Antisocial Behavior in Organizations, 37, 67.

Nicholls, J. (1984). Conceptions of Ability and Achievement Motivation. In R. Ames, \& C. Ames (Eds.), Research on Motivation in Education: Student Motivation (Vol. 1, pp. 3973). New York: Academic Press.

Nicholls, J. G. (1989). The Competitive Ethos and Democratic Education. Cambridge, MA: Harvard University Press.

Ntoumanis, N., \& Biddle, S. J. (1999). A Review of Motivational Climate in Physical Activity. Journal of Sports Sciences, 17, 643-665.

http://dx.doi.org/10.1080/026404199365678

Ommundsen, Y., \& KvalØ, S. E. (2007). Autonomy-Mastery, Supportive or Performance Focused? Different Teacher Behaviours and Pupils' Outcomes in Physical Education. Scandinavian Journal of Educational Research, 51, 385-413. http://dx.doi.org/10.1080/00313830701485551

Onyekwere, E. O., Rubin, R. B., \& Infante, D. A. (1991). Interpersonal Perception and Communication Satisfaction as a Function of Argumentativeness and Ego-Involvement. Communication Quarterly, 39, 35-47. https://doi.org/10.1080/01463379109369781

Papaioannou, A. (1994). Development of a Questionnaire to Measure Achievement 
Orientations in Physical Education. Research Quarterly for Exercise and Sport, 65, 11 20. https://doi.org/10.1080/02701367.1994.10762203

Papaioannou, A. (1995). Differential Perceptual and Motivational Patterns When Different Goals Are Adopted. Journal of Sport and Exercise Psychology, 17, 18-34. https://doi.org/10.1123/jsep.17.1.18

Papaioannou, A. (1998). Goal Perspectives, Reasons for Being Disciplined, and Self-Reported Disciple in Physical Education Lessons. Journal of Teaching in Physical Education, 17, 421-441. https://doi.org/10.1123/jtpe.17.4.421

Papaioannou, A., Marsh H. W., \& Theodorakis, Y. (2004). A Multilevel Approach to Motivational Climate in Physical Education and Sport Settings: An Individual or a Group Level Construct. Journal of Sport and Exercise Psychology, 26, 90-118. https://doi.org/10.1123/jsep.26.1.90

Rancer, A. S. and Infante, D. A. (1985) Relations between Motivation to Argue and Argumentativeness of Adversaries. Communication Quarterly, 33, 209-218. https://doi.org/10.1080/01463378509369599

Rancer, A. S., \& Avtgis, T. A. (2006). Argumentative and Aggressive Communication: Theory, Research, and Application. Thousand Oaks, California: Sage Publications.

Rancer, A. S., \& Avtgis, T. A. (2014). Argumentative and Aggressive Communication: Theory, Research, and Application (2nd ed.). New York: Peter Lang.

Rancer, A. S., Avtgis, T. A., Kosberg, R. L., Whitecap, V. G. (2000). A Longitudinal Assess-ment of Trait Argumentativeness and Verbal Aggressiveness between Seventh and Eighth Grades. Communication Education, 49, 114-119. https://doi.org/10.1080/03634520009379197

Roach, K. D. (1992). Teacher Demographic Characteristics and Levels of Teacher Argumentativeness. Communication Research Reports, 9, 65-71. https://doi.org/10.1080/08824099209359898

Roberts, G. C. (2012). Motivation in Sport and Exercise from an Achievement Goal Theory Perspective: After 30 Years, Where Are We? In G. Roberts, \& D. Treasure (Eds.), Advances in Motivation in Sport and Exercise (3rd ed., pp. 5-58). Champaign, IL: Human Kinetics.

Roberts, G. C., \& Treasure, D. C. (1992). Children in Sport. Sport Science Review, 1, 4664.

Roberts, G. C., Treasure, D., \& Conroy, D. E. (2007). Understanding the Dynamics of Motivation in Sport and Physical Activity: An Achievement Goal Interpretation. In G. Tenenbaum, \& R. Eklund (Eds.), Handbook of Sport Psychology (3rd ed., pp. 3-30). Hoboken, NJ: Wiley. https://doi.org/10.1002/9781118270011.ch1

Rocca, K. A. (2004). College Student Attendance: Impact of Instructor Immediacy and Verbal Aggression. Communication Education, 53, 185-195. http://dx.doi.org/10.1080/03634520410001682447

Schrodt, P. (2003). Student Perceptions of Instructor Verbal Aggressiveness: The Influence of Student Verbal Aggressiveness and Self-Esteem. Communication Research Reports, 20, 240-250. http://dx.doi.org/10.1080/08824090309388822

Smith, R. E., Smoll, F. L., \& Cumming, S. P. (2007). Effects of a Motivational Climate Intervention for Coaches on Young Athletes' Sport Performance Anxiety. Journal of Sport and Exercise Psychology, 29, 39-59. http://dx.doi.org/10.1123/jsep.29.1.39

Snyder, J., Forbus, R., \& Cistulli, M. (2012). Attendance Policies, Student Attendance, and Instructor Verbal Aggressiveness. Journal of Education for Business, 87, 145-151.

http://dx.doi.org/10.1080/08832323.2011.582192 
Spittle, M., \& Byrne, K. (2009). The Influence of Sport Education on Student Motivation in Physical Education. Physical Education and Sport Pedagogy, 14, 253-266. http://dx.doi.org/10.1080/17408980801995239

Standage, M., \& Gillison, F. (2007). Students' Motivational Responses toward School Physical Education and Their Relationship to General Self-Esteem and Health-Related Quality of Life. Psychology of Sport and Exercise, 8, 704-721.

https://doi.org/10.1016/j.psychsport.2006.12.004

Syrmpas, I., \& Bekiari, A. (2015). The Relationship between Perceived Physical Education Teacher's Verbal Aggressiveness and Argumentativeness with Students' Interpersonal Attraction. Inquiries in Sport \& Physical Education, 13, 21-32.

Theodosiou, A., Mantis, K., \& Papaioannou, A. (2008). Student Self-Reports of Metacognitive Activity in Physical Education Classes. Age-Group Differences and the Effect of Goal Orientations and Perceived Motivational Climate. Educational Research and Review, 3, 353-364.

Theoharis, D., \& Bekiari, A. (2017). Applying Social Network Indicators in the Analysis of Verbal Aggressiveness at the School. Journal of Computer and Communications, 5, 169-181. http://dx.doi.org/10.4236/jcc.2017.57015

Theoharis, D., \& Bekiari, A. (2018). Dynamic Analysis of Verbal Aggressiveness Networks in School. Open Journal of Social Sciences, 16, 14-28.

http://dx.doi.org/10.4236/jss.2018.61002

Theoharis, D., Bekiari, A., \& Koustelios, A. (2017). Exploration of Determinants of Verbal Aggressiveness and Leadership through Network Analysis and Conventional Statistics. Using School Class as an Illustration. Sociology Mind, 7, 27-43. http://dx.doi.org/10.4236/sm.2017.72003

Treasure, D. C., \& Roberts, G. C. (1995). Applications of Achievement Goal Theory to Physical Education: Implications for Enhancing Motivation. Quest, 47, 475-489. https://doi.org/10.1080/00336297.1995.10484170

Van De Pol, P. K. C., Kavussanu, M., \& Ring, C. (2012). Goal Orientations, Perceived Motivational Climate, and Motivational Outcomes in Football: A Comparison between Training and Competition Contexts. Psychology of Sport and Exercise, 13, 491-499. http://dx.doi.org/10.1016/j.psychsport.2011.12.002

Vazou, S., Ntoumanis, N., \& Duda, J. L. (2005). Peer Motivational Climate in Youth Sport: A Qualitative Inquiry. Psychology of Sport and Exercise, 6, 497-516. http://dx.doi.org/10.1016/j.psychsport.2004.03.005

Weiss, M. R., Amorose, A. J., \& Wilko, A. M. (2009). Coaching Behaviors, Motivational Climate, and Psychosocial Outcomes among Female Adolescent Athletes. Pediatric exercise science, 21, 475-492. http://dx.doi.org/10.1123/pes.21.4.475

Weiss, S., \& Houser, M. (2007). Student Communication Motives and Interpersonal Attraction toward Instructor. Communication Research Reports, 3, 215-224. https://doi.org/10.1080/08824090701439091

Wigley, C. J. III, Pohl, G. H., \& Watt, M. G. S. (1989). Conversational Sensitivity as a Correlate of Trait Verbal Aggressiveness and the Predisposition to Verbally Praise Others. Communication Reports, 2, 92-95. https://doi.org/10.1080/08934218909367488

Wrench, J. S., \& Punyanunt-Carter, N. M. (2005). Advisor-Advisee Communication Two: The Influence of Verbal Aggression and Humor Assessment on Advisee Perceptions of Advisor Credibility and Affective Learning. Communication Research Reports, 22, 303-313. http://dx.doi.org/10.1080/000368105000317599 